\title{
Reduced Poliovirus Vaccine Neutralising-Antibody titres in Infants with Maternal HIV- exposure
}

Marta Sanz-Ramos, ${ }^{1+}$ Daniela Manno, ${ }^{2+}$ Mirriam Kapambwe,${ }^{3}$ Ida Ndumba ${ }^{3}$ Kunda G. Musonda, ${ }^{1,3}$

Matthew Bates, ${ }^{1}$ Julia Chibumbya, ${ }^{4}$ Joshua Siame, ${ }^{3}$ Mwaka Monze, ${ }^{3}$ Suzanne Filteau, ${ }^{2}$ and Ursula

A. Gompels ${ }^{{ }^{*}}$ and CIGNIS study team.

${ }^{1}$ Departments of Pathogen Molecular Biology and ${ }^{2}$ Nutrition \& Public Health Intervention

Research, London School of Hygiene and Tropical Medicine, U.K. ${ }^{3}$ Virology Unit and ${ }^{4}$ Chilenje

Clinic, University Teaching Hospital, Lusaka, Zambia.

${ }^{*}$ Corresponding author,${ }^{+}$These authors had equal contributions

Running title: Maternal HIV, HCMV \& Child Polio Vaccine

Corresponding author contact details: Dr UA Gompels, Department of Pathogen Molecular

Biology, London School of Hygiene \& Tropical Medicine, University of London, Keppel St,

London WC1E 7HT, UK . Telephone: +44(0)2079272315

Email: ursula.gompels@1shtm.ac.uk

Word counts: abstract 291; text 3300; figures/table 6

Keywords: maternal HIV exposure; childhood HIV; polio vaccine; human cytomegalovirus; micronutrient; breastfeeding 


\section{Abstract}

Background: Maternally HIV-exposed (mHIV-EU) infants have poor health even without HIV-1 infection. The responses to vaccination are less well defined. Immunity to oral Poliovirus vaccine (OPV) was studied in Zambian infants participating in a randomised controlled trial of micronutrient fortification to improve child health. Method: Maternally HIV-unexposed and mHIV-EU infants were recruited at 6 months age and randomised to basal or enriched micronutrient-fortified diets for 12 months. HIV-exposed mother-infant pairs had received perinatal nevirapine to prevent mother-to-child-transmission. In the cohort of 597 infants, neutralising-antibody titres to OPV were analysed at 18 months with respect to micronutrient fortification, maternal or infant HIV-1 infection, and human cytomegalovirus (HCMV) infection detected by antibodies and viremia (serum DNA). Vaccine protection was defined as $\log _{2}$ titre $>3$. Results: Compared to uninfected children, HIV-1-infected children had reduced neutralising antibody titres to OPV, irrespective of diet: $\log _{2}$ titre difference $(95 \%$ confidence interval $)-3.44(-2.41 ;-4.46) \mathrm{p}<0.01$. OPV antibody titres were lower in HIV-infected children with HCMV viremia compared to those without viremia at 18 months, but did not reach significance: difference $-2.55(-6.10 ; 1.01) \mathrm{p}=0.14$. Breastfeeding duration was independently associated with increasing OPV titre (pvalue $<0.01)$. In mHIV-EU children there were reduced neutralising antibody titres to poliovirus compared with maternally HIV-unexposed, irrespective of diet, maternal education and socioeconomic status: $\log _{2}$ titre difference ( $95 \%$ confidence interval) $-0.56(-0.98 ;-0.15)$ $\mathrm{p}<0.01$. This difference was noticeably decreased after adjusting for breast-feeding duration, suggesting that in our study population less breast-feeding by HIV-positive mothers could explain the reduced OPV titres in mHIV-EU infants. Conclusion: The mHIV-EU infants had reduced polio vaccine antibody titres which were associated with reduced breast-feeding duration. This has important implications for polio eradication and control of vaccine- 
preventable diseases, in countries where childhood HIV-1 infection and maternal exposure are public health threats.

\section{Highlights}

- Both maternally HIV-exposed and infected infants had reduced neutralisingantibodies to polio vaccine

- The proportion of antibody-titres below protective levels were increased in both maternally HIV-exposed and infected infants.

- Trial of micronutrient fortification in 743 randomised infants had no effect on vaccine antibody titre

- We report effects of breast-feeding and HCMV infection on reduced antibody titres 


\section{Introduction}

HIV-1 exposure in infants is a major public health challenge in developing countries, particularly in Sub-Saharan Africa which has $90 \%$ of infected paediatric cases worldwide. Limited access to preventive methods and antiretroviral treatments increases HIV-1 transmission and worsens disease outcome [1]. Children with HIV-1/AIDS may show lower protection against vaccine-preventable infections relative to HIV-1 uninfected children. Causes include lower vaccine coverage [2]; and impaired capacity to produce or maintain adequate levels of antibodies against vaccines [3-7]. Additional threats are opportunistic pathogens. Human cytomegalovirus (HCMV) is a major viral opportunistic infection in HIV1 positive infants, and has been associated with HIV-1/AIDS progression, severe morbidity and mortality [8-9]. Furthermore, in Europe, in elderly populations, HCMV is associated with 'senescence' of the immune system leading to decreased naïve T-lymphocytes, increased differentiated memory T-lymphocytes, and reduced ability to respond to new infections [10]. Leukocytes with these phenotypes are also observed in African countries, in children from the Gambia and Malawi, after HCMV infections which here are earlier, during infancy, and more prevalent, suggesting effects on these cells at an early age could affect response to other infections during childhood [11-12]. In studies of infants with congenital HCMV infections, there were reduced lymphocyte responses to HCMV, but not to herpes simplex virus [13]. It is possible that the modified leukocytes identified in postnatally acquired HCMV African infants may also affect immunity to other challenges, including vaccines.

Recent studies show HIV-1-negative infants born to HIV-1-positive mothers (maternally exposed uninfected, mHIV-EU) also display altered immunity [14-16] and increased disease risk, including higher prevalence of high-load HCMV infections, which in some patient 
groups are linked with pathology $[8-9,15]$. Nevertheless, few investigations address their vaccine responses. For example, one study shows after vaccination, mHIV-EU infants presented lower anti-tetanus antibody titres and increased non-responders to hepatitis B vaccine, than unexposed infants, but no difference in diphtheria vaccine responses [17]. Another investigation showed little difference in mHIV-EU infants antibody responses after routine vaccination against Haemophilus Influenzae type b, pneumococcus, tetanus toxoid and hepatitis B surface antigen [18]. This apparent contradiction and the lack of knowledge on this subject highlights the need for further investigation.

Poliomyelitis is a priority vaccine-preventable disease worldwide. Despite great success in eradication, three countries remain with endemic Poliovirus (Afghanistan, Nigeria and Pakistan), and several more with imported Poliovirus [19-20]. A current major concern is that the oral polio vaccine, OPV, efficacy at inducing protective-antibodies against Poliovirus is suboptimal in developing countries [21]. Furthermore, immunogenicity may be reduced in transition to inactivated Poliovirus vaccine, IPV, in countries trying to maintain polio-free status. Diverse factors have been suggested to contribute to this deficient antibody response, such as enteric pathogens interference with OPV responses, high levels of maternal antibodies, vaccination during rainy season, and immunodeficiency syndromes [20, 22]. Nonetheless, the role of HIV-1 in reduced OPV immune-responses in developing countries remains controversial, in contrast to characterised effects of weaker responses to vaccines, such as measles, the combined diphtheria, tetanus and whole-cell pertussis (DTwP) [3, 23]. Only limited studies have investigated childhood HIV-1 effects and impaired immune responses to OPV [5, 23]. Moreover, vaccine efficacy has not been evaluated in infants with maternal HIV-1 exposure but without HIV-1 infection (mHIV-EU) nor in HIV-exposed infants using anti-retroviral (ART) treatments, under new programs to prevent mother-to- 
child-transmission (MTCT). These mHIV-EU infants are the majority of children affected by maternal exposure to HIV-1. Where antenatal HIV-1 infection is between $20-25 \%$ as in Zambia, mHIV-EU infants are a large proportion of all births [24-25].

We have evaluated the neutralising-antibody response to OPV in HIV-infected, mHIV-EU and HIV-unexposed Zambian infants included in a randomised double-blind controlled micronutrient trial. Zambia is a polio-free country, but is in danger of importing the virus from polio-endemic countries. In addition, there is high HIV-1/AIDS prevalence, increasing the importance of ensuring complete OPV coverage and high levels of protective antibodies. The main aim of the trial was to investigate the efficacy of micronutrient fortification to prevent stunting of infants [26]. Here, as a planned secondary outcome we analyzed neutralising antibody responses to OPV. In addition, we have investigated how maternal HIV-exposure, infant HIV-1, HCMV infection and breast-feeding influence the OPV neutralising-antibody response, given the interactions described above. We hypothesised that infant HCMV and HIV-1 co-infection, and possibly HCMV infection in mHIV-EU children, could have synergistic negative effects on OPV protective-antibody responses. 


\section{Methods}

\subsection{Study design and population}

The Chilenje Infant Growth, Nutrition and Infection Study (CIGNIS) was a randomized double-blind controlled trial comparing two micronutrient food-fortifications, 'rich' or 'basal' (Registered clinical trial ISRCTN37460449) [26]. The trial was conducted in Chilenje, Lusaka, Zambia, from October 2005 to July 2009. Children were randomised to one of the two fortified-porridges at age 6 months, and were followed for 12 months. A total of 811 infants were enrolled in the study with 743 correctly randomised [26].

\subsection{Poliovirus vaccination and assay for Poliovirus antibody-neutralization titres}

The OPV schedule followed national campaigns with inoculations at birth, 6, 10 and 14 weeks age. Infants missing the first dose were given a booster at 9 months age. All study children had a further boost at 12 months. Poliovirus type 2 neutralizing-antibody titres were determined at 18 months as described [27] with modifications. Serial two-fold dilutions of sera, inactivated at $56^{\circ} \mathrm{C}$ for 30 minutes, were incubated with $200 \mathrm{TCID}_{50}$ of Poliovirus type 2 challenge virus (MEF, vaccine reference strain of Poliovirus 2) in 96-microwell plates at $36^{\circ} \mathrm{C}$ for $1 \mathrm{~h}$. After the incubation, $100 \mu \mathrm{l}$ of L20B cell suspension was added to each well, and incubated at $36^{\circ} \mathrm{C}$ for minimum 5 days. Presence or absence of cytopathic effect (CPE) was recorded and antibody titres calculated as the highest dilution of serum protecting $50 \%$ of the cultures against challenge virus. Positive correlates of protection were neutralizationantibody titres $\geq 8$ (1:8 dilution, $\log _{2} 3$ ) cut-offs [27].

\subsection{HIV-1 testing}

Maternal HIV-1 status was obtained from government health service antenatal HIV-1 antibody testing records. HIV-1 positive mothers had received short course intrapartum 
Nevirapine, as local standard of care to reduce childhood transmission, MTCT [28]. Seventy women had unknown antenatal HIV status. All children at 18 months were tested for HIVantibody using a serial testing algorithm. Samples were tested using Determine HIV 1/ 2 (Inverness Medical, Japan) with any negative results recorded, positive results were re-tested using Unigold HIV 1/ 2 (Trinity Biotech plc, Ireland), with confirmed-positive results recorded. If negative, i.e. discordant, a third test SD-Bioline HIV $1 / 2$ (Standard Diagnostics, Korea) was used as final result.

\subsection{HCMV antibody and DNA testing}

The ETI-CYTOK-G PLUS ELISA Kit (DiaSorin) was used for detection of anti-HCMV IgG in human serum. Standard curves were plotted with control serum standards; sample IgG titres above a cut-off $0.4 \mathrm{IU} / \mathrm{ml}$ were considered positive as shown [29]. Qualitative and quantitative polymerase chain reactions (PCR) were performed using HCMV glycoprotein gB (UL55) specific-primers on sera DNA extracted with QIAamp DNA Blood Mini Kit (Qiagen) as described. Possible variability in DNA yields by hemolysis in sera collection were analysed by quantitative real time assays for human GAPDH gene, this showed no evidence for effects of hemolysis. Furthermore specificity and reproducibility were checked by reconstructions of virus genes in sera establishing standard curves for the real time analyes $[8,29]$.

\subsection{Statistical analyses}

Data were double-entered and verified in Access. Range and logical checks were run in Access and in Stata (Version 12, Statacorp, College Station, TX, USA). OPV neutralisingantibody titre was $\log 2$ transformed and compared between diet and HIV exposure groups using the unpaired t-test. In addition, the proportion of infants with seroprotective levels of 
OPV specific neutralising-antibody ( $\log 2$ titre $<3=$ un-protective and $\geq 3$ protected) was compared between groups using chi-squared test or Fisher's exact test when smallest expected-value was $<5$. Socioeconomic status (SES) was measured using an asset index, created by combining data on possessions and housing characteristics using principal component analysis [26]. To guide analyses, a conceptual framework was developed to identify the main pathways by which maternal-HIV status can influence OPV neutralisingantibody response (Figure 1). Multivariable analysis was conducted using linear regression and logistic regression when the outcome was $\log 2$ OPV neutralising-antibody titre and seroprotective levels of OPV antibody, respectively.

\subsection{Multiple imputation analyses}

Among the 811 infants enrolled in the trial, 597 (73\%) infants at 18 months had available OPV neutralising-antibody results. Missing data were mainly due to loss to follow up at 18 months (23\%) and inadequate infant serum sample volume (an additional 5\%) (Figure 2). HCMV IgGs and HMCV DNA were measured respectively in available subsample of 460 (57\%) and 428 (53\%) infants at 18 months age. Only 444 (54\%) infants had both HCMV IgGs and OPV antibodies response available, while 414 (51\%) had HMCV DNA and OPV response available. Multiple imputations with chained equations methods were used to account for any missing data. Known covariates including those associated with loss to follow up (maternal age and HIV status) and Poliovirus-antibody response (child HIV-status, anaemia, stunting, mother's education, socioeconomic status, breast-feeding duration) (see Table 1) were used to impute 10 data-sets. All continuous variables used in the imputation were normally distributed; socioeconomic status, mother's education and breast-feeding duration were treated as ordered categorical variables. In addition to the main analyses of observed data, complete analyses were conducted with all imputed data. 


\subsection{Ethics statement}

All mothers gave informed, written consent for the study. Ethical approval for the trial was given by the Ethics committees of University Teaching Hospital, Lusaka, Zambia and London School of Hygiene and Tropical Medicine. 


\section{Results}

\subsection{Micronutrient-fortification and OPV antibody response}

A total of 743 infants were recruited and randomised (Figure 2); of those $373(50.2 \%)$ were in the 'basal' and $370(49.8 \%)$ in the 'rich' micronutrient-fortified arm. Trial arms were substantially balanced at baseline (supplemental Table 1), with no difference in loss to follow-up by 18 months $(\mathrm{P}=0.88)$. The percentage of infants of HIV-uninfected women was higher among those lost to follow-up (77\%) than among those who completed the study (68\%), but these groups were otherwise similar [26].

Overall and in sub-groups defined by maternal and child HIV-serostatus, there was no evidence $(\mathrm{P}>0.05)$ of an effect of rich-fortified, compared with basal-fortified arm, on OPV neutralising-antibody titres (Figure 3) or in the proportion of infants with un-protective levels of antibodies $(\log 2$ titre $<3)$ after OPV $(2 \%$ in basal and $3 \%$ in rich micronutrient-fortified arm, $\mathrm{P}=0.74$ ). Results were confirmed after multiple-imputations analysis (data not shown).

\subsection{Breastfeeding and other characteristics associated with OPV antibody response}

There was strong evidence $(\mathrm{p}<0.01)$ of increasing Poliovirus neutralising-antibody titres with increasing breast-feeding duration. Smaller effects were seen in titres of Poliovirusantibodies which were slightly lower in infants who were stunted (Length for age $<-2 \mathrm{Z})(\mathrm{P}<$ $0.01)$ or anaemic $(\mathrm{Hb}<105 \mathrm{~g} / \mathrm{L})(\mathrm{P}=0.01)$ at 18 months. There was also some evidence for lower OPV antibody-titres in low birth weight infants $(\mathrm{P}=0.06)$. Infants of more educated mothers had better antibody responses to OPV, with evidence of linear trend across maternal education categories $(\mathrm{P}=0.02)$. Socioeconomic status of the mother, sex, HCMV seropositivity and HCMV DNA positivity at 18 months of the infants were not associated with titre of Poliovirus antibodies and proportion of infants with un-protective antibodies 
levels, respectively. The above results were confirmed using imputed datasets (data not shown).

\subsection{Child HIV infection}

Among the 597 infants with available OPV antibody response, $17(2.8 \%)$ tested HIV positive (Figure 2, Table 1). In univariable analysis, titres of Poliovirus antibodies were significantly lower $(\mathrm{P}<0.01)$ in HIV-seropositive compared with HIV-seronegative infants. The proportion of infants with un-protective levels of antibodies $(\log 2$ titre $<3)$ was also higher $(35 \%)$ in HIV-seropositive, than in HIV-seronegative infants $(1.6 \%, \mathrm{p}<0.01)$ (Table 1). Almost all HIV positive infants were breastfed (Table 1S), highlighting the risk of infection through this route. Women who were HIV-positive showed some awareness of this and had modified their own breastfeeding patterns compared to HIV-uninfected women; $25 \%$ of HIV-infected women never breastfed whereas almost all HIV-uninfected women breastfed [30]. These differences were further evaluated in effects of maternal HIV exposure on OPV titres.

\subsection{Maternal HIV exposure}

Among the 547 mothers with known HIV-serostatus, 150 (27.4\%) were HIV-positive (Table 1, Figure 2). The overall effect of maternal HIV status on antibody response to OPV (pathway $\mathrm{a}+\mathrm{b}+\mathrm{c}$ in Figure 1, included HIV-positive infants) showed that maternal HIVserostatus was significantly associated with both lower titres of Poliovirus-antibodies $(\mathrm{P}<0.01)$ and a higher proportion of infants with un-protective Poliovirus-antibody levels $(\log 2$ titre $<3)$ after OPV $(\mathrm{P}<0.01)($ Table 1$)$.

The effect of maternal HIV infection on Poliovirus-antibody titres not dependent on infant HIV status (pathway $\mathrm{b}+\mathrm{c}$ in Figure 1), was then analysed including only HIV-uninfected 
infants (Table 2). Maternal-HIV was still associated with reduced Poliovirus-antibody titres, even after adjusting for maternal education and socioeconomic status (adjusted difference $-0.56,95 \% \mathrm{CI}[-0.98 ;-0.15], \mathrm{P}<0.01)$. We then explored the effect of maternal HIV infection on Poliovirus-antibodies not dependent on breast-feeding duration (pathway c in Figure 1). Duration of breast-feeding was significantly shorter in HIV-positive mothers compared to HIV-negative (median 6 months vs 15 months, $\mathrm{P}<0.01$ ). Longer breastfeeding duration was associated with increased antibody titre to OPV, independent of socioeconomic status, maternal education and trial arm (Table 2). After adjusting for breast-feeding duration, the effect of maternal HIV exposure on Poliovirus antibody titres was removed (adjusted difference $-0.03,95 \% \mathrm{CI}[-0.59 ; 0.64], \mathrm{P}=0.93$ ) (Table 2). These results were confirmed after multiple imputations using imputed data-sets. The imputed regression coefficient for a linear trend between breast-feeding and Poliovirus antibody titre after adjusting for trial arm, maternal HIV-status, education and socioeconomic status was 0.42 [95\% CI $0.12 ; 0.72]$ $\mathrm{p}<0.01$. The association with maternal HIV was again removed after further adjustment for breast-feeding duration: imputed regression coefficient of $0.29[95 \% \mathrm{CI}-0.50 ; 1.09] \mathrm{P}=0.47$ ).

Regarding the effect of maternal-HIV status on proportion of HIV-uninfected infants with unprotective levels of antibodies $(\log 2$ titre $<3$ ) (pathway $\mathrm{b}+\mathrm{c}$ in figure 3 ), after adjusting for maternal education and socioeconomic status, mHIV-EU infants had slightly, but not significantly, increased odds of having an unprotective level of antibodies after OPV (OR $2.68,95 \% \mathrm{CI}[0.65 ; 11.10], \mathrm{P}=0.17)$. This also decreased to $1.04,95 \% \mathrm{CI}[0.14 ; 7.61]$, $\mathrm{P}=0.97$, after breast-feeding duration adjustment.

Therefore, the overall analyses show breast-feeding duration was able to explain most of the observed differences in antibody titres between mHIV-EU and unexposed-uninfected infants. 


\subsection{HCMV antibody and DNA positivity}

Among the 597 infants with available OPV antibody response, 414 also had HCMV serum DNA results, and $414 \mathrm{HCMV}$ antibody results at 18 months age. Of these, $148(35.7 \%)$ had HCMV viraemia (positive HCMV DNA) indicating active infection, while $369(83.1 \%)$ had antibodies against HCMV documenting a previous exposure to the virus. In our study, we found no evidence of an association between antibody response to OPV and both HCMV DNA positivity and serostatus (Table 1). However, in the $5 \mathrm{HIV}$-infected infants with HCMV viraemia at 18 months there was a suggestion of lower OPV-antibody titres compared to the 8 infants without HCMV viremia (Table 3). There was no OPV-antibody titre difference between mHIV-EU or HIV-unexposed infants who were HMCV DNA-positive or negative. HCMV seropositivity at 18 months had no effect on OPV titres in HIV-positive $(\mathrm{P}=0.49)$ and mHIV-EU infants ( $\mathrm{P}=0.98$ ) (Table 3). While in HIV-unexposed infants, there was a suggestion of increased OPV antibody titre in HCMV seropositive infants $(\mathrm{P}=0.11)$. 


\section{Discussion}

Our study has documented that infant HIV-1 infection is associated with an impaired neutralising antibody response to OPV. Notably, over 35\% of the HIV-positive children did not have protective-antibody levels against Poliovirus infection at 18 months of age despite receiving an extra vaccine-booster at 12 months age. In childhood HIV-1 primary infections, the loss of $\mathrm{CD}^{+} \mathrm{T}$-lymphocytes linked to the peak of viraemia, and subsequent erosion of the immune system, may affect induction and maintainance of immunological memory to OPV $[3-5,23]$. Furthermore, HIV-1-infected infants are highly susceptible to infections that may either interfere with the vaccine antibody-response, or may alternatively exacerbate HIV-1 effects, as our results show an indication of this from HCMV co-infection.

Antibody response to OPV at 18 months was not influenced by the provision from 6 to 18 months of micronutrient-fortified infant-food, in the overall study population or any maternal/child HIV sub-groups. In our trial, rich compared to basal micronutrientfortification was able to improve iron status, reduced anaemia, and increased serum selenium, but did not reduce stunting and was associated with increased occurrence of lower respiratory tract infections [26, 31].

Importantly, this study shows that maternal HIV-1 exposure was associated with reduced neutralising-antibody response to OPV also in HIV-uninfected infants. Breast-feeding duration was independently associated with these reduced titres. This is important since many HIV-infected women stop breast-feeding early; $25 \%$ HIV-infected mothers, compared to $0.5 \% \mathrm{HIV}$-uninfected mothers, never breastfed with medians of 6 vs 15 months breastfeeding, respectively. With adjustment for breast-feeding duration, most differences in OPV titre were removed, suggesting that in our study population, lower breast-feeding duration by HIV-positive mothers could explain reduced OPV titres in mHIV-EU infants. 
Breast-feeding was previously associated with better humoral response to OPV and other vaccines, such as diphtheria, tetanus toxoids and Haemophilus influenzae type b vaccine, although HIV-effects were not analysed [32-33]. Despite evidence that formula-fed babies compared to breastfed babies had increased responses to poliovirus type 3 in Brazil [34], the effects of maternal HIV-status were not assessed and there were no differences with type 2 which were analysed here. Reduced OPV titres in mHIV-EU infants could be due to reduced antibody transfer via breast-feeding in HIV-1 positive mothers, from reduced duration or reduced antibody production. Breast-feeding also promotes immune system development [35]. Alternatively, the OPV titres may be affected from high exposure of mHIV-EU infants to infectious agents that can be transmitted via breast milk, or via saliva during close contacts between mother and child, both routes for HCMV.

HCMV was further investigated as a factor affecting OPV titres in HIV-infected or exposed infants. HCMV is a main viral opportunistic infection in HIV-infected children, can account for pathology leading to morbidity/mortality, and is a marker for AIDS progression [9]. HCMV has also been linked with immune alterations which may affect the ability to respond to new infections [10-12]. In our study, there appeared negative synergistic effects between infant HIV infection and HCMV active infection but the analyses were limited by low numbers. In this cohort, HCMV infection also associated with reduced growth [29], but with no evidence of a synergistic effect between maternal HIV-exposure and HCMV previous or current infection on OPV antibody response. However, there was a suggestion of higher OPV titres in maternally HIV-unexposed children who had previous HCMV infection, suggesting a potential immunostimulatory effect, possibly a factor in breastmilk; this was not seen amongst maternally HIV-exposed children. 
The impaired immune response to OPV of HIV-1-positive and mHIV-EU infants has important implications not only in the control of poliomyelitis from wild-type Poliovirus, but also in outbreaks caused by vaccine-derived Polioviruses (VDPVs). OPV is a live-attenuated vaccine that can cause infection in immunocompromised individuals. Replication in the host may lead to revertants, recombinant and/or mutant VDPVs with increased pathogenicity, which together with the continuous shedding of virus in infected individuals provide sources for new outbreaks [36]. Where there is reduced Poliovirus immunization the risk of wildtype Poliovirus and VDPV outbreaks increases. Thus, in regions with high HIV-1/AIDS prevalence, such as Sub-Saharan Africa, it is of great importance to ensure good Poliovirus vaccine coverage and adequate immune responses. For example, increasing doses of Poliovirus vaccine (OPV or IPV) in those children with un-protective neutralising-antibody titres, could improve their vaccine immune response [5]. Although weaker immune responses to OPV were observed, robust titres above the correlate of protection cut-off were in the majority of the cohort $(97.5 \%, 582 / 597)$, with unprotective titres mainly in the HIV-infected infants $(35 \%, 6 / 17)$ compared to mHIV-EU $(4 \%, 5 / 133)$ and the unexposed $(1 \%, 4 / 397)$.

The limitations to the interpretation of the study, also point towards an underestimate of the effects of maternal HIV-1 exposure on efficacy of OPV. Although we did not follow immunisation adherence, all study infants were given an additional OPV dose at 12 months age, therefore maternal HIV-exposure effects on OPV may be more pronounced on standard regimens; while in Zambia polio vaccine coverage is high (96\%, WHO survey 2009). Responses were only measured to serotype 2 , which are characteristically strong; serotype 3 responses, usually weaker than to serotype 2 after OPV [27], could be more affected by HIVexposure. Finally, only the attenuated-live OPV was used; the killed vaccine, IPV, in use for 
some eradication programmes for safety, may be more sensitive to maternal HIV-1 exposure. The specific effects of maternal HIV-exposure and HIV-1 infection on different vaccines and the underlying mechanisms, such as negative effects of early HCMV infection with HIV-1, or immune-benefit of breastfeeding, need further investigation. Mechanisms may include effects on antibody, such as IgA, as well as benefit from innate regulation through NK cell and cytokine components of breastmilk. Although breastfeeding was associated with better OPV responses and has a clear public health message, this has to be in tandem with measures to prevent pathogens such as HIV or HCMV transmitted in breastmilk.

Clinical recommendations from this study are that maternally HIV-exposed in addition to HIV-infected children should be monitored for Poliovirus vaccine efficacy, and additional doses given as required, particularly in the absence of breast-feeding. This may apply generally to vaccines for mHIV-EU infants. Moreover, in countries where highly prevalent and early infant infections with HCMV are seen, such as several African countries in addition to Zambia, the effects of childhood HIV-1 infection may be more severe in reduction of OPV efficacy and need consideration in vaccination programs. 


\section{Acknowledgements}

This work was supported by the Bill and Melinda Gates Foundation, grant ID 37253. The authors report no conflict of interest in this study. We thank all the mothers and their children who participated in the study, Lusaka District Health staff for support, and all members of the

CIGNIS study team: Principal Investigator: Suzanne Filteau, London School of Hygiene and Tropical Medicine (LSHTM) ; Zambian Lead Investigator: Lackson Kasonka, University Teaching Hospital (UTH), Lusaka; Senior Investigators: Rosalind Gibson, University of Otago, New Zealand; Ursula A. Gompels, LSHTM; Shabbar Jaffar, LSHTM; Emmanuel Kafwembe, Tropical Diseases Research Centre, Ndola; Mwaka Monze, UTH; Moses Sinkala, Catholic Relief Services, Zambia; Andrew Tomkins, Institute of Child Health, University College, London; Rodah Zulu, National Institute of Science and Industrial Research, Zambia; Clinic Coordinator: Molly Chisenga; Clinical Officer: Joshua Siame; Data Manager: Hildah Banda Mabuda; Statisticians: Kathy Baisley, Helen Dale, Natasha Larke, Daniela Manno, Andrea Rehman; Research Fellows: Matthew Bates, Anne Mullen, Kunda Musonda, Marta Sanz-Ramos; Clinic Staff: Hellen Kangwa Bwalya, Margaret Chileshe, Priscilla Kangwa Kowa, Mabvuto Kumwenda, Munalula Likando, Sydney Mambwe, Mutinta Muzyamba, Anne Mwale, Lungowe Nyaywa; Laboratory Staff: Humphrey Bima, Julia Chibumbya, Laura Gosset, Louise Hackett, Abigail Jackson, Mirriam Kapambwe, Mazyanga Liewe, Sydney Mwanza, Ida Ndumba, Eric Njunju; Data Entry: Concillia Kabanga, Natalia Shampwaya; Drivers and Cleaners: John Chobo, Winford Kapumba, Charity Musonda, Philip Soko. 


\section{References}

[1] Granich R, Crowley S, Vitoria M, Lo YR, Souteyrand Y, Dye C, et al. Highly active antiretroviral treatment for the prevention of HIV transmission. J Int AIDS Soc 2010;13:1.

[2] Setse RW, Cutts F, Monze M, Ryon JJ, Quinn TC, Griffin DE, et al. HIV-1 infection as a risk factor for incomplete childhood immunization in Zambia. J Trop Pediatr 2006 Oct;52(5):324-8.

[3] Bekker V, Scherpbier H, Pajkrt D, Jurriaans S, Zaaijer H, Kuijpers TW. Persistent humoral immune defect in highly active antiretroviral therapy-treated children with HIV-1 infection: loss of specific antibodies against attenuated vaccine strains and natural viral infection. Pediatrics 2006 Aug;118(2):e315-22.

[4] Pancharoen C, Ananworanich J, Thisyakorn U. Immunization for persons infected with human immunodeficiency virus. Curr HIV Res 2004 Oct;2(4):293-9.

[5] Tejiokem MC, Gouandjika I, Beniguel L, Zanga MC, Tene G, Gody JC, et al. HIV-infected children living in Central Africa have low persistence of antibodies to vaccines used in the Expanded Program on Immunization. PLoS One 2007;2(12):e1260.

[6] Abzug MJ, Warshaw M, Rosenblatt HM, Levin MJ, Nachman SA, Pelton SI, et al. Immunogenicity and immunologic memory after hepatitis B virus booster vaccination in HIV-infected children receiving highly active antiretroviral therapy. J Infect Dis 2009 Sep 15;200(6):935-46.

[7] Tejiokem MC, Njamkepo E, Gouandjika I, Rousset D, Beniguel L, Bilong C, et al. Wholecell pertussis vaccine induces low antibody levels in human immunodeficiency virus-infected children living in sub-Saharan Africa. Clin Vaccine Immunol 2009 Apr;16(4):479-83.

[8] Bates M, Monze M, Bima H, Kapambwe M, Kasolo FC, Gompels UA. High human cytomegalovirus loads and diverse linked variable genotypes in both HIV-1 infected and exposed, but uninfected, children in Africa. Virology 2008 Dec 5;382(1):28-36.

[9] Kovacs A, Schluchter M, Easley K, Demmler G, Shearer W, La Russa P, et al. Cytomegalovirus infection and HIV-1 disease progression in infants born to HIV-1-infected women. 
Pediatric Pulmonary and Cardiovascular Complications of Vertically Transmitted HIV Infection Study Group. N Engl J Med 1999 Jul 8;341(2):77-84.

[10] Pawelec G, Derhovanessian E, Larbi A, Strindhall J, Wikby A. Cytomegalovirus and human immunosenescence. Rev Med Virol 2009 Jan;19(1):47-56.

[11] Ben-Smith A, Gorak-Stolinska P, Floyd S, Weir RE, Lalor MK, Mvula H, et al. Differences between naive and memory $\mathrm{T}$ cell phenotype in Malawian and UK adolescents: a role for Cytomegalovirus? BMC Infect Dis 2008;8:139.

[12] Miles DJ, van der Sande M, Jeffries D, Kaye S, Ismaili J, Ojuola O, et al. Cytomegalovirus infection in Gambian infants leads to profound CD8 T-cell differentiation. J Virol 2007 Jun;81(11):5766-76.

[13] Pass RF, Stagno S, Britt WJ, Alford CA. Specific cell-mediated immunity and the natural history of congenital infection with cytomegalovirus. J Infect Dis 1983 Dec;148(6):953-61.

[14] Bunders M, Thorne C, Newell ML. Maternal and infant factors and lymphocyte, CD4 and CD8 cell counts in uninfected children of HIV-1-infected mothers. AIDS 2005 Jul 1;19(10):1071-9.

[15] Clerici M, Saresella M, Colombo F, Fossati S, Sala N, Bricalli D, et al. T-lymphocyte maturation abnormalities in uninfected newborns and children with vertical exposure to HIV. Blood 2000 Dec 1;96(12):3866-71.

[16] Miyamoto M, Pessoa SD, Ono E, Machado DM, Salomao R, Succi RC, et al. Low CD4+ Tcell levels and B-cell apoptosis in vertically HIV-exposed noninfected children and adolescents. J Trop Pediatr 2010 Dec;56(6):427-32.

[17] Abramczuk BM, Mazzola TN, Moreno YM, Zorzeto TQ, Quintilio W, Wolf PS, et al. Impaired humoral response to vaccines among HIV-exposed uninfected infants. Clin Vaccine Immunol 2011 Sep;18(9):1406-9.

[18] Jones CE, Naidoo S, De Beer C, Esser M, Kampmann B, Hesseling AC. Maternal HIV infection and antibody responses against vaccine-preventable diseases in uninfected infants. JAMA 2011 Feb 9;305(6):576-84.

[19] 2010 [cited; Available from:

http://apps.who.int/immunization_monitoring/en/globalsummary/countryprofileselect.cfm 
[20] Minor PD. The polio-eradication programme and issues of the end game. J Gen Virol 2012 Mar;93(Pt 3):457-74.

[21] Okayasu H, Sutter RW, Czerkinsky C, Ogra PL. Mucosal immunity and poliovirus vaccines: impact on wild poliovirus infection and transmission. Vaccine 2011 Oct 26;29(46):8205-14.

[22] Polio vaccines and polio immunization in the pre-eradication era: WHO position paper. Wkly Epdemiol Rec;85:213-28.

[23] Ryder RW, Oxtoby MJ, Mvula M, Batter V, Baende E, Nsa W, et al. Safety and immunogenicity of bacille Calmette-Guerin, diphtheria-tetanus-pertussis, and oral polio vaccines in newborn children in Zaire infected with human immunodeficiency virus type 1. J Pediatr 1993 May;122(5 Pt 1):697-702.

[24] Stringer EM, Chintu NT, Levy JW, Sinkala M, Chi BH, Muyanga J, et al. Declining HIV prevalence among young pregnant women in Lusaka, Zambia. Bull World Health Organ 2008 Sep;86(9):697-702.

[25] Stringer EM, Ekouevi DK, Coetzee D, Tih PM, Creek TL, Stinson K, et al. Coverage of nevirapine-based services to prevent mother-to-child HIV transmission in 4 African countries. JAMA 2010 Jul 21;304(3):293-302.

[26] Team CS. Micronutrient fortification to improve growth and health of maternally HIVunexposed and exposed Zambian infants: a randomised controlled trial. PLoS One 2010;5(6):e11165. [27] Herremans MM, Reimerink JH, Ras A, Van Der Avoort HG, Kimman TG, Van Loon AM, et al. Evaluation of a poliovirus-binding inhibition assay as an alternative to the virus neutralization test. Clin Diagn Lab Immunol 1997 Nov;4(6):659-64.

[28] Chi BH, Sinkala M, Mbewe F, Cantrell RA, Kruse G, Chintu N, et al. Single-dose tenofovir and emtricitabine for reduction of viral resistance to non-nucleoside reverse transcriptase inhibitor drugs in women given intrapartum nevirapine for perinatal HIV prevention: an open-label randomised trial. Lancet 2007 Nov 17;370(9600):1698-705.

[29] Gompels UA, Larke N, Sanz-Ramos M, Bates M, Musonda K, Manno D, et al. Human cytomegalovirus infant infection adversely affects growth and development in maternally HIVexposed and unexposed infants in Zambia. Clin Infect Dis 2012 Feb 1;54(3):434-42. 
[30] Chisenga M, Siame J, Baisley K, Kasonka L, Filteau S. Determinants of infant feeding choices by Zamian mothers: a mixed quantitative and qualitative study. Maternal and Child Nutrition 2010;7(2):148-59.

[31] Gibson RS, Kafwembe E, Mwanza S, Gosset L, Bailey KB, Mullen A, et al. A micronutrientfortified food enhances iron and selenium status of Zambian infants but has limited efficacy on zinc. J Nutr 2011 May;141(5):935-43.

[32] Hahn-Zoric M, Fulconis F, Minoli I, Moro G, Carlsson B, Bottiger M, et al. Antibody responses to parenteral and oral vaccines are impaired by conventional and low protein formulas as compared to breast-feeding. Acta Paediatr Scand 1990 Dec;79(12):1137-42.

[33] Pabst HF, Spady DW. Effect of breast-feeding on antibody response to conjugate vaccine. Lancet 1990 Aug 4;336(8710):269-70.

[34] Factors affecting the immunogenicity of oral poliovirus vaccine: a prospective evaluation in Brazil and the Gambia. World Health Organization Collaborative Study Group on Oral Poliovirus Vaccine. J Infect Dis 1995 May;171(5):1097-106.

[35] Palmer AC. Nutritionally mediated programming of the developing immune system. Adv Nutr 2011 Sep;2(5):377-95.

[36] Rakoto-Andrianarivelo M, Gumede N, Jegouic S, Balanant J, Andriamamonjy SN, Rabemanantsoa S, et al. Reemergence of recombinant vaccine-derived poliovirus outbreak in Madagascar. J Infect Dis 2008 May 15;197(10):1427-35. 
Table 1. Univariable association OPV antibody response and characteristics of the infants and their mothers.

\begin{tabular}{|c|c|c|c|c|c|c|}
\hline & $\begin{array}{l}n(\%) \\
N=597^{a}\end{array}$ & $\begin{array}{l}\text { Mean poliovirus } \\
\text { antibody titre (SD) }\end{array}$ & $\begin{array}{l}\text { Difference } \\
(95 \% \mathrm{CI})\end{array}$ & $P^{\mathrm{b}}$ & $\begin{array}{l}\text { Vaccine } \\
\text { Failure } \\
(\%)^{c}\end{array}$ & $P^{\mathrm{d}}$ \\
\hline \multicolumn{7}{|c|}{ Infant's characteristics } \\
\hline \multicolumn{7}{|l|}{ Sex } \\
\hline male & $281(47.1)$ & $7.91(2.21)$ & & & $7(2.5)$ & \\
\hline female & $316(52.9)$ & $8.17(2.16)$ & $0.26(0.60 ;-0.09)$ & 0.17 & $8(2.5)$ & 0.99 \\
\hline \multicolumn{7}{|l|}{ Birth weight ${ }^{\mathrm{e}}$} \\
\hline$\geq 2.5 \mathrm{Kg}$ & $508(85.7)$ & $8.13(2.13)$ & & & $12(2.4)$ & \\
\hline$<2.5 \mathrm{Kg}$ & $85(14.3)$ & $7.64(2.41)$ & $-0.49(-0.99 ; 0.01)$ & 0.06 & $3(3.5)$ & 0.52 \\
\hline \multicolumn{7}{|c|}{ Stunting at 18 months $^{\mathrm{f}}$} \\
\hline no & $476(79.9)$ & $8.18(2.17)$ & & & $12(2.5)$ & \\
\hline yes & $120(20.1)$ & $7.51(2.23)$ & $-0.67(-1.10 ;-0.23)$ & $<0.01$ & $3(2.5)$ & 0.99 \\
\hline \multicolumn{7}{|c|}{ Anaemia at the assessment ${ }^{\mathrm{g}}$} \\
\hline no & $409(69.2)$ & $8.20(2.13)$ & & & $7(1.7)$ & \\
\hline yes & $182(30.8)$ & $7.70(2.29)$ & $-0.50(-0.12 ;-0.88)$ & 0.01 & $8(4.4)$ & 0.05 \\
\hline \multicolumn{7}{|l|}{ HIV serostatus } \\
\hline negative & $580(97.2)$ & $8.15(2.09)$ & & & $9(1.6)$ & \\
\hline positive & $17(2.8)$ & $4.71(2.97)$ & $-3.44(-2.41 ;-4.46)$ & $<0.01$ & $6(35.3)$ & $<0.01$ \\
\hline \multicolumn{7}{|c|}{ HCMV serostatus at 18 months ${ }^{\mathrm{h}}$} \\
\hline negative & $75(16.9)$ & $7.87(2.29)$ & & & $3(4.0)$ & \\
\hline positive & $369(83.1)$ & $8.13(2.09)$ & $0.26(0.79 ;-0.27)$ & 0.33 & $5(1.4)$ & 0.14 \\
\hline \multicolumn{7}{|c|}{ HCMV DNA at 18 months $^{\mathrm{i}}$} \\
\hline negative & $266(64.3)$ & $8.05(2.21)$ & & & $5(1.9)$ & \\
\hline positive & $148(35.7)$ & $7.87(2.29)$ & $-0.04(0.40 ;-0.49)$ & 0.85 & $5(3.4)$ & 0.35 \\
\hline \multicolumn{7}{|c|}{ Breast feeding duration } \\
\hline Never & $42(7.0)$ & $6.86(2.28)$ & & & $1(2.4)$ & \\
\hline$<6$ months & $56(9.4)$ & $7.52(2.32)$ & $0.66(-0.27 ; 1.59)$ & & $3(5.4)$ & \\
\hline 6-11 months & $70(11.7)$ & $7.77(2.54)$ & $0.91(-0.03 ; 1.86)$ & & $7(9.9)$ & \\
\hline $12-17$ months & $242(40.6)$ & $8.27(2.12)$ & $1.41(-0.71 ; 2.12)$ & & $4(1.7)$ & \\
\hline$\geq 18$ months & $187(31.3)$ & $8.30(2.12)$ & $1.44(-0.76 ; 2.13)$ & $<0.01^{\mathrm{j}}$ & $0(0.0)$ & $0.23^{\mathrm{k}}$ \\
\hline \multicolumn{7}{|c|}{ Mother's characteristics } \\
\hline \multicolumn{7}{|c|}{ HIV status ${ }^{1}$} \\
\hline negative & $397(72.6)$ & $8.27(2.12)$ & & & $4(1.0)$ & \\
\hline positive & $150(27.4)$ & $7.31(2.36)$ & $-0.96(-0.55 ;-1.37)$ & $<0.01$ & $10(6.7)$ & $<0.01$ \\
\hline \multicolumn{7}{|l|}{ Education } \\
\hline none /primary & $187(31.3)$ & $7.77(2.11)$ & & & $5(2.7)$ & \\
\hline secondary & $236(39.5)$ & $8.09(2.17)$ & $0.32(-0.10 ; 0.74)$ & & $6(2.5)$ & \\
\hline college/university & $174(29.2)$ & $8.29(2.29)$ & $0.52(0.08 ; 0.98)$ & $0.02^{\mathrm{j}}$ & $4(2.3)$ & $0.81^{\mathrm{j}}$ \\
\hline \multicolumn{7}{|l|}{ Socioeconomic status } \\
\hline low & $191(32.0)$ & $8.02(2.11)$ & & & $4(2.1)$ & \\
\hline middle & $234(39.2)$ & $7.91(2.28)$ & $-0.11(-0.52 ; 0.32)$ & & $7(3.0)$ & \\
\hline high & $172(28.8)$ & $8.27(2.16)$ & $0.25(-0.20 ; 0.71)$ & 0.25 & $4(2.3)$ & 0.82 \\
\hline
\end{tabular}

${ }^{a}$ Including 52 infants with available Poliovirus antibodies results among those not appropriately randomised. ${ }^{b} P-$ value obtained by linear regression adjusting for treatment arm. ${ }^{\mathrm{c}}$ Number (\%) infants with OPV antibody log2 titre $<3$. ${ }^{\mathrm{d}} \mathrm{P}$-value obtained by logistic regression adjusting for treatment arm. ${ }^{\mathrm{e}}$ Information was missing for 4 infants. ${ }^{\mathrm{f}}$ Length for age $<-2 \mathrm{Z}$; not available for one infant. ${ }^{\mathrm{g}}$ Haemoglobin $<105 \mathrm{~g} / \mathrm{L}$; information was missing for 6 infants. ${ }^{h}$ Not available for 153 infants. $\dagger \dagger$ Not available for 183 infants. ${ }^{\mathrm{i}}$ Test for trend. Test for departure from linear trend $\mathrm{P}$-value $>0.05$. ${ }^{\mathrm{k}}$ Test for trend $\mathrm{P}$-value. Test for departure from linear trend $\mathrm{P}$-value $=0.02$. ${ }^{1}$ Reported or from clinical records; for 50 mothers HIV status was unknown. 
Table 2.

Multivariable association mean $\log 2$ antibody titre after OPV and maternal HIV and breastfeeding in HIV-uninfected infants ${ }^{\mathrm{a}}$

\begin{tabular}{|c|c|c|c|c|c|c|c|}
\hline & $\begin{array}{c}\mathrm{n}(\%) \\
\mathrm{N}=530^{\mathrm{a}}\end{array}$ & $\begin{array}{l}\text { Difference } \\
(95 \% \mathrm{CI})\end{array}$ & $P^{\mathrm{b}}$ & $\begin{array}{l}\text { Adjusted Difference } \\
\text { (breastfeeding } \\
\text { excluded) } \\
(95 \% \mathrm{CI})\end{array}$ & $P^{\mathrm{b}}$ & $\begin{array}{l}\text { Adjusted Difference } \\
\text { (breastfeeding } \\
\text { included) } \\
(95 \% \mathrm{CI})\end{array}$ & $P^{\mathrm{b}}$ \\
\hline \multicolumn{8}{|l|}{$\begin{array}{l}\text { Mother HIV } \\
\text { status }^{c}\end{array}$} \\
\hline negative & 397 (74.9) & & & & & & \\
\hline positive & $133(25.1)$ & $-0.62(-1.04 ;-0.21)$ & $<0.01$ & $-0.56(-0.98 ;-0.15)$ & $<0.01$ & $-0.03(-0.59 ; 0.64)$ & 0.93 \\
\hline \multicolumn{8}{|l|}{$\begin{array}{l}\text { Maternal } \\
\text { education }\end{array}$} \\
\hline none /primary & $162(30.6)$ & 0 (baseline) & & 0 (baseline) & & 0 (baseline) & \\
\hline secondary & $208(39.2)$ & $0.41(-0.02 ; 0.84)$ & & $0.36(-0.09 ; 0.80)$ & & $0.42(-0.03 ; 0.87)$ & \\
\hline college/university & $160(30.2)$ & $0.61(0.15 ; 1.07)$ & $0.01^{\mathrm{d}}$ & $0.51(0.00 ; 1.03)$ & $0.05 \S$ & $0.58(0.06 ; 1.09)$ & $0.03^{\mathrm{d}}$ \\
\hline \multicolumn{8}{|l|}{$\begin{array}{l}\text { Socioeconomic } \\
\text { status }\end{array}$} \\
\hline low & $171(32.3)$ & 0 (baseline) & & 0 (baseline) & & 0 (baseline) & \\
\hline middle & $205(38.7)$ & $0.08(-0.35 ; 0.51)$ & & $-0.10(-0.55 ; 0.34)$ & & $-0.03(-0.48 ; 0.41)$ & \\
\hline high & $154(29.0)$ & $0.32(-0.15 ; 0.78)$ & 0.37 & $0.03(-0.48 ; 0.54)$ & $0.91 \S$ & $0.14(-0.37 ; 0.65)$ & $0.60^{\mathrm{d}}$ \\
\hline \multicolumn{8}{|l|}{ Breast feeding } \\
\hline Never & $38(7.2)$ & 0 (baseline) & & & & 0 (baseline) & \\
\hline$<6$ months & $51(9.6)$ & $0.58(-0.30 ; 1.46)$ & & - & & $0.67(-0.22 ; 1.56)$ & \\
\hline 6-11 months & $59(11.1)$ & $1.01(0.15 ; 1.86)$ & & - & & $1.03(0.13 ; 1.92)$ & \\
\hline 12-17 months & $217(41.0)$ & $1.20(0.47 ; 1.92)$ & & - & & $1.23(0.30 ; 2.15)$ & \\
\hline$\geq 18$ months & $165(31.1)$ & $1.28(0.54 ; 2.02)$ & $<0.01^{\mathrm{d}}$ & - & & $1.39(0.46 ; 2.33)$ & $<0.01^{\mathrm{d}}$ \\
\hline
\end{tabular}

${ }^{a}$ Model based on 530 HIV-negative infants with available $\log 2$ antibody titre.${ }^{b} P$-value obtained by linear regression adjusting also for treatment arm. ${ }^{\mathrm{c}}$ Reported or from clinical records. ${ }^{\mathrm{d}}$ Test for trend. Test for departure from linear trend P-value $>0.05$. 
Table 3.

Effect of HCMV DNA or antibody positivity at 18 months on OPV neutralizingantibody response stratified by infant HIV and maternal HIV-exposure.

\begin{tabular}{|c|c|c|c|c|c|c|}
\hline \multicolumn{7}{|c|}{$\log _{2}$ poliovirus antibody titre } \\
\hline & $\mathrm{N}(\%)$ & $\operatorname{Mean}(\mathrm{SD})^{\mathrm{a}}$ & $\begin{array}{l}\text { Difference } \\
(95 \% \mathrm{CI})\end{array}$ & $\begin{array}{c}\mathrm{P} \\
\text { value }\end{array}$ & $\begin{array}{l}\text { Vaccine } \\
\text { failures }{ }^{b} \\
(\%)\end{array}$ & $\begin{array}{c}\mathrm{P} \\
\text { value }\end{array}$ \\
\hline HIV-positive infants & $N=13^{\mathrm{c}}$ & & & & & \\
\hline HCMV DNA positive & $5(38.5)$ & $3.20(1.30)$ & & & $2 / 5(25.0)$ & \\
\hline HCMV DNA negative & $8(61.5)$ & $5.75(3.41)$ & $-2.55(-6.10 ; 1.01)$ & 0.14 & $2 / 8(40.0)$ & 1.00 \\
\hline$H I V-m E U$ infants & $N=84^{\mathrm{c}}$ & & & & & \\
\hline HCMV DNA positive & $28(33.3)$ & $7.79(2.33)$ & & & $1 / 28(3.6)$ & \\
\hline HCMV DNA negative & $56(66.7)$ & $7.54(2.05)$ & $0.25(-0.74 ; 1.24)$ & 0.62 & $2 / 56(3.6)$ & 1.00 \\
\hline $\begin{array}{l}\text { HIV-maternally } \\
\text { unexposed }\end{array}$ & $N=284^{\mathrm{c}}$ & & & & & \\
\hline HCMV DNA positive & $103(36.3)$ & $8.29(2.14)$ & & & $2 / 103(1.9)$ & \\
\hline HCMV DNA negative & $181(63.7)$ & $8.25(2.15)$ & $0.04(-0.48 ; 0.55)$ & 0.89 & $1 / 181(0.6)$ & 0.30 \\
\hline HIV-positive infants & $N=9^{\mathrm{d}}$ & & & & & \\
\hline HCMV seropositive & $7(77.8)$ & $4.43(2.37)$ & & & $2 / 7(28.5)$ & \\
\hline HCMV seronegative & $2(22.2)$ & $6.00(4.24)$ & $-1.57(-6.72 ; 3.58)$ & 0.49 & $0 / 2(0.0)$ & 1.00 \\
\hline$H I V$-mEU infants & $N=94^{\mathrm{d}}$ & & & & & \\
\hline HCMV seropositive & $76(80.9)$ & $7.79(2.00)$ & & & $2 / 76(2.6)$ & \\
\hline HCMV seronegative & $18(19.1)$ & $7.78(2.13)$ & $0.01(-1.04 ; 1.06)$ & 0.98 & $1 / 18(5.6)$ & 0.47 \\
\hline $\begin{array}{l}\text { HIV-maternally } \\
\text { unexposed }\end{array}$ & $N=302^{\mathrm{d}}$ & & & & & \\
\hline HCMV seropositive & $255(84.4)$ & $8.31(2.07)$ & & & $1 / 255(0.4)$ & \\
\hline HCMV seronegative & $47(15.6)$ & $7.77(2.36)$ & $0.53(-0.12 ; 1.20)$ & 0.11 & $2 / 47(4.3)$ & 0.06 \\
\hline
\end{tabular}

${ }^{a}$ Mean of $\log _{2}$ polio neutralising antibody titres and the standard deviation (SD) is in brackets. ${ }^{b}$ Titres below correlate of protection, $\log 2<3 .{ }^{\text {C }}$ Polio Ab titre and HCMV DNA were only available in 13 HIVpositive infants, 84 HIV-mEU infants and $284 \mathrm{HIV}$-maternally unexposed infants. For $33 \mathrm{HIV}$-uninfected infants with available Polio Ab titre and HCMV DNA, maternal HIV status was unknown, therefore they

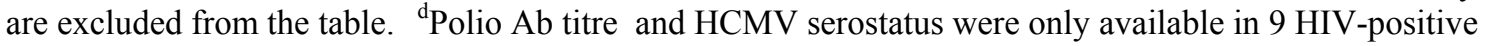
infants, 94 HIV-mEU infants and 302 HIV-maternally unexposed infants. For 39 HIV-uninfected infants with available Polio Ab titre and HCMV serostatus, maternal HIV status was unknown, therefore they are excluded from the table. 
Supplemental table 1. Description of the CIGNIS study population at recruitment

\begin{tabular}{|c|c|c|}
\hline & $\begin{array}{l}\text { Basal-fortified porridge } \\
\qquad N=373\end{array}$ & $\begin{array}{l}\text { Rich-fortified porridge } \\
\qquad \mathrm{N}=370\end{array}$ \\
\hline \multicolumn{3}{|l|}{ Infant's characteristics } \\
\hline Sex male & $191(51)$ & $166(45)$ \\
\hline Birth weight (kg) & $3.05(0.50)$ & $3.05(0.46)$ \\
\hline Stunted at 6 months (length for age $<-2 \mathrm{Z}$ ) & $51(14)$ & $40(11)$ \\
\hline \multicolumn{3}{|l|}{ Breastfeeding duration: } \\
\hline never & $22(6)$ & $21(6)$ \\
\hline$<6$ months & $39(11)$ & $29(8)$ \\
\hline breastfeeding at recruitment & $312(84)$ & $320(87)$ \\
\hline Anemia, $\mathrm{Hb}<105 \mathrm{~g} / \mathrm{L}$ & $140(38)$ & $149(41)$ \\
\hline \multicolumn{3}{|l|}{ Mother's characteristics } \\
\hline \multicolumn{3}{|l|}{ Maternal antenatal HIV status* } \\
\hline Negative & $261(70)$ & $258(70)$ \\
\hline Positive & $79(21)$ & $78(21)$ \\
\hline Unknown & $33(9)$ & $34(9)$ \\
\hline Mother's age (years) & $26.0(5.7)$ & $26.4(5.8)$ \\
\hline \multicolumn{3}{|l|}{ Mother's education } \\
\hline primary or less & $123(33)$ & $129(35)$ \\
\hline secondary & $157(42)$ & $127(34)$ \\
\hline college/university & $93(25)$ & $114(31)$ \\
\hline \multicolumn{3}{|l|}{ Mother's occupation } \\
\hline housewife & $214(57)$ & $181(49)$ \\
\hline salaried employee & $61(16)$ & $86(23)$ \\
\hline self-employed & $39(11)$ & $31(8)$ \\
\hline other & $59(16)$ & $72(20)$ \\
\hline \multicolumn{3}{|l|}{ Marital status } \\
\hline married & $278(75)$ & $279(75)$ \\
\hline single & $79(21)$ & $72(20)$ \\
\hline divorced, separated, widowed & $16(4)$ & $19(5)$ \\
\hline \multicolumn{3}{|l|}{ Tertiles of socioeconomic status } \\
\hline 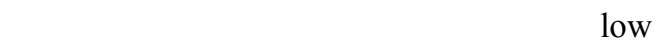 & $127(34)$ & $123(33)$ \\
\hline middle & $151(40)$ & $136(37)$ \\
\hline high & $95(25)$ & $111(30)$ \\
\hline
\end{tabular}

Continuous variables summarized as mean (SD). Categorical variables summarized as number in groups (\%).

*Six infants of mothers HIV-uninfected antenatally and one of an HIV-unknown mother tested HIV-infected by 18 months old.

Adapted from Filteau et al. (2009) PloS one. 


\section{Figure Legends}

Figure 1. Conceptual framework guiding the analyses which shows the main pathways maternal HIV status can influence antibody response to OPV. The overall effect (pathway a + $b+c)$, was explored including HIV-positive infants in the analysis, while the effect of maternal HIV infection not dependent on infant HIV status (pathway $b+c$ ), was obtained restricting the analysis to HIV-uninfected infants only. In HIV-uninfected infants, we then explored the effect of maternal HIV infection on Poliovirus neutralising-antibodies not dependent on breast-feeding duration adjusting by breastfeeding duration in the multivariable analysis (pathway c).

Figure 2. Flow diagram displaying infants recruited in CIGNIS trial, those lost to follow up and those tested at 18 months for OPV neutralising-antibody response by treatment arm. 743/811 were correctly randomised [26], and those with OPV titres are included in the trial analyses. The 68 non-randomised children are also included where the trial was not the priority focus; 52 of these had available poliovirus-antibody results. Therefore, to assess the effect of child and maternal HIV infection on OPV antibody response, these were included in the analysis (Figure 1).

Figure 3. $\log 2$ antibody titre by micronutrient-fortification treatment arm, stratified by HIVinfection and maternal HIV-exposure in uninfected infants. Numbers on the bars are sample sizes in each group. 
Figure 1

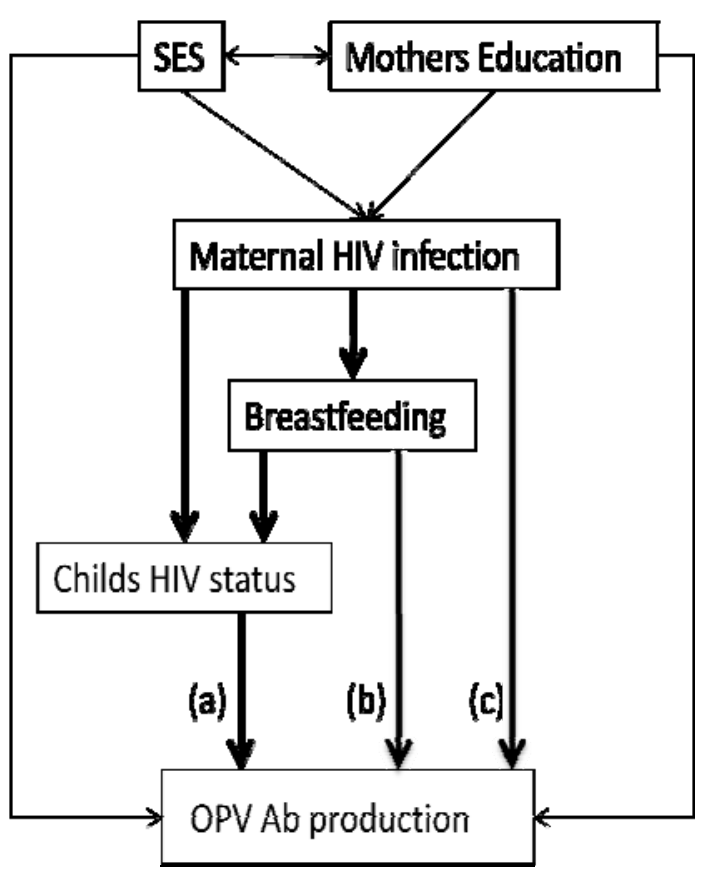


Figure 2

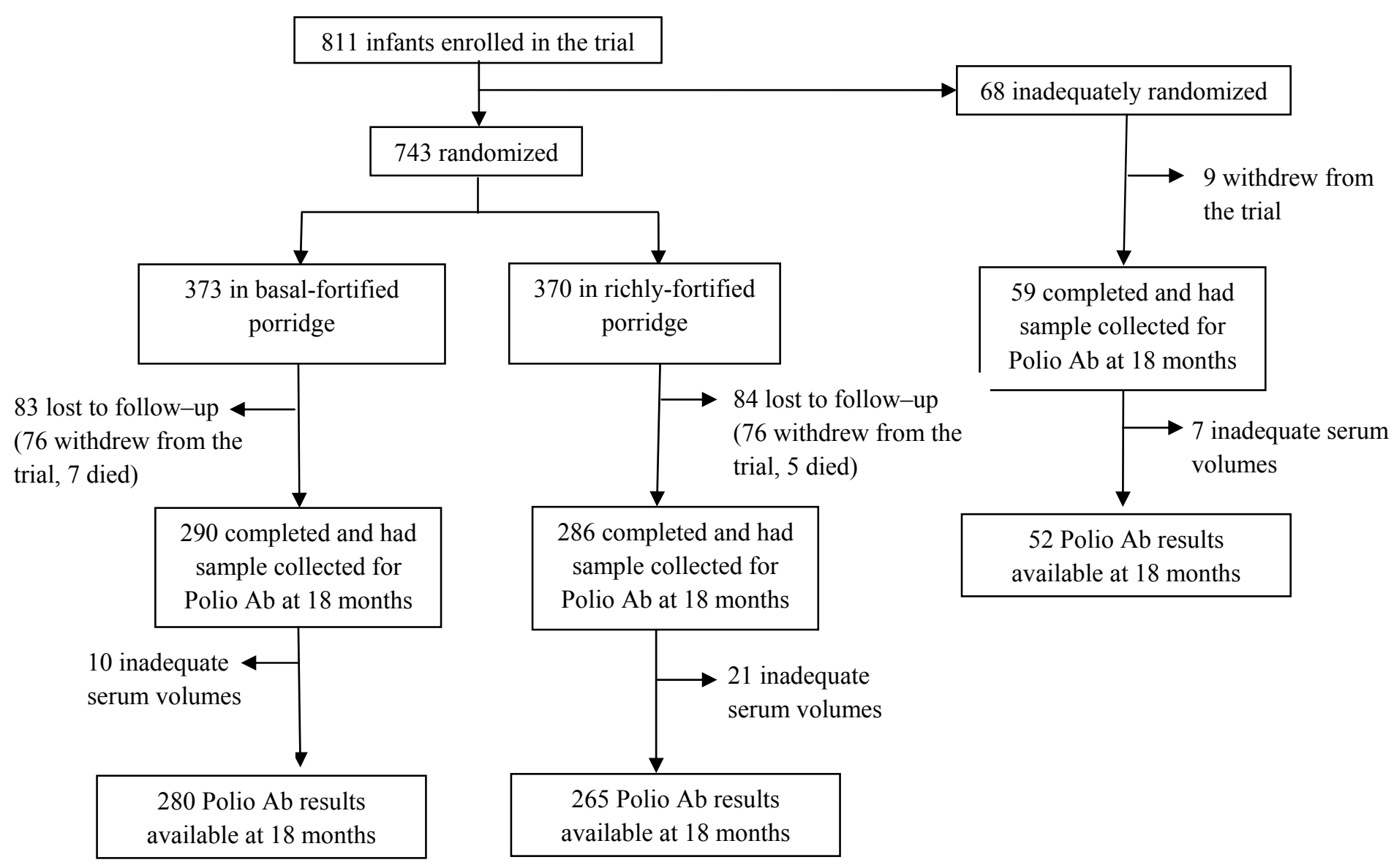


Figure 3

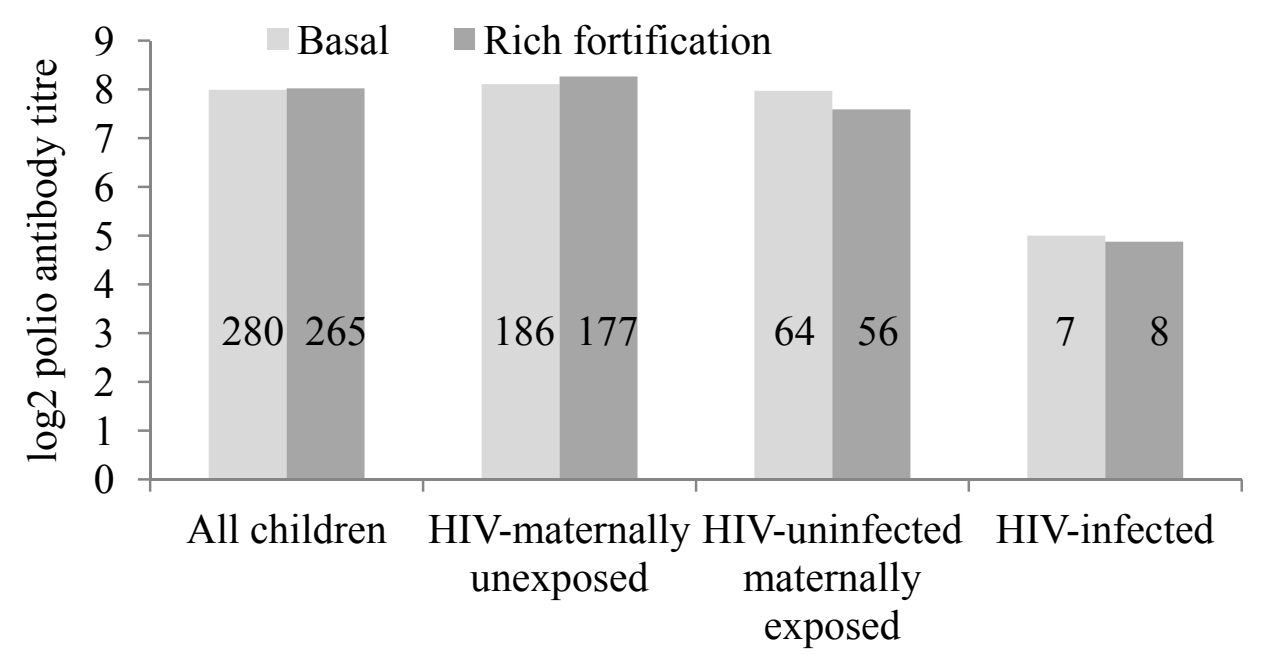


Supplemental Table

Table 1S.

Duration of breastfeeding in HIV+ infants

Breastfeeding duration $\mathrm{N}(\%)$

Never $2(11.76 \%)$

$<6$ months $\quad 3(17.65 \%)$

6-11 months $\quad 5(29.41 \%)$

12-17 months $\quad 4(23.54 \%)$

$18+$ months $\quad 3(17.65 \%)$

Total

$17(100 \%)$ 